\title{
Composição centesimal e conteúdo mineral de diferentes cultivares de feijão biorfortificado (Phaseolus vulgaris $L$.)
}

\section{Proximate composition and mineral content of different cultivars of biofortified beans (Phaseolus vulgaris L.)}

\author{
Frederico Lovato ${ }^{1 *}$, Jussara Kowaleski' ${ }^{1}$, Sabrine Zambiazi da Silva ${ }^{2}$, Leila Fernanda Serafini Heldt ${ }^{3}$ \\ ${ }_{1}^{1}$ Fundação para o Desenvolvimento Científico e Tecnológico Universidade (Fundetec), Laboratório de Análises, Cascavel/PR - Brasil \\ 2 Fundação para o Desenvolvimento Científico e Tecnológico Universidade (Fundetec), Divisão de Projetos, Cascavel/PR - Brasil \\ ${ }^{3}$ Serviço Nacional de Aprendizagem Industrial (SENAI), Área de Alimentos e Bebidas, Cascavel/PR - Brasil
}

\section{${ }^{*}$ Corresponding Author}

Frederico Lovato, Fundação para o Desenvolvimento Científico e Tecnológico Universidade (Fundetec), Laboratório de Análises, Rodovia BR 277, km 573, Caixa Postal: 120, CEP: 85818-560, Cascavel/PR - Brasil, e-mail: frederico@fundetec.org.br

Cite as: Proximate composition and mineral content of different cultivars of biofortified beans (Phaseolus vulgaris L.). Braz. J. Food Technol., v. 21, e2017068, 2018

Received: May 12, 2017; Accepted: Aug. 24, 2017

\section{Resumo}

O feijão é uma das principais fontes de proteína e de ferro, além de outros nutrientes, e por ser, também, um alimento de fácil acesso e preparo, faz com que o Brasil seja um dos maiores consumidores e produtores de feijão comum (Phaseolus vulgaris, L.). Estudos apontam que a anemia é o problema nutricional mais grave no Brasil e a inserção de alimentos básicos biofortificados pode auxiliar na redução desse quadro. O objetivo deste trabalho foi analisar, bem como comparar, estatisticamente, a composição centesimal e os teores de minerais dos grãos crus e cozidos das cultivares de feijão comercializadas - tipo preto e carioca - e das cultivares biofortificadas - BRS esplendor e BRS pontal. Os grãos crus triturados e os grãos cozidos foram avaliados quanto aos teores de umidade, cinzas, proteína, lipídios e carboidratos, e os minerais ferro, potássio, magnésio e sódio. Os resultados obtidos foram submetidos à análise de variância e as médias foram comparadas pelo teste de Tukey $(p<0,05)$. A utilização de feijão biofortificado é promissora para diminuir a incidência de anemias, pois os resultados obtidos mostram que a biofortificação aumentou os teores de ferro, potássio e magnésio.

Palavras-chave: Anemia; Desnutrição; Proteína; Ferro.

\section{Abstract}

Brazil is one of the largest consumers and producers of the common bean (Phaseolus vulgaris, L.), one of the major sources of protein and iron and other nutrients, besides being easy to cultivate and cook. Studies have shown anaemia to be the most serious nutritional problem in Brazil and the inclusion of biofortified basic foods could help in reducing it. The objective of this paper was to analyse and statistically compare the proximate composition and mineral content of raw and cooked grains of two bean cultivars: black and pinto, and two biofortified cultivars: BRS esplendor and BRS pontal The ground raw beans and the cooked beans were evaluated with respect to their moisture, ash, protein, lipids, carbohydrates, iron, potassium, magnesium and sodium contents. The results were submitted to an analysis of variance and the means compared by the Tukey test $(p<0.05)$. The use of biofortified beans is of promise to reduce the incidence of anaemia, since the results showed that biofortification increased the iron, potassium and magnesium contents.

Keywords: Anaemia; Malnutrition; Protein; Iron.

\section{Introdução}

A legislação brasileira afirma que existem duas espécies de feijão, que são cultivadas no Brasil: o feijão comum, espécie Phaseolus vulgaris (L.), e o feijão-caupi, espécie
Vigna unguiculata (L.) Walp. Destaca-se o tipo carioca, que representa $70 \%$ do mercado consumidor brasileiro, seguido pelo tipo preto, com 20\% (BRASIL, 2008; PELOSO; MELO, 2005). 
A importância do feijão na alimentação brasileira é devida à facilidade da inserção diária deste alimento na dieta. O consumo do produto, em média, por pessoa, chega a 19 quilos por ano, sendo uma excelente fonte proteica, além de possuir bom conteúdo de carboidratos, vitaminas (principalmente as do complexo B), minerais, como ferro, cálcio, magnésio, fósforo e zinco, fibras e compostos fenólicos com ação antioxidante, que podem reduzir a incidência de doenças (SILVA et al., 2009).

Além de apresentar substâncias nutritivas essenciais para o organismo, a leguminosa pode também conter uma variedade de substâncias antinutricionais, que interferem nos processos de digestibilidade, absorção ou utilização de nutrientes; dessa forma, se ingeridos em altas concentrações, podem acarretar efeitos danosos à saúde (SANTOS, 2006; BENEVIDES et al., 2011). Os principais compostos antinutricionais presentes no feijão são os taninos, que têm habilidade em precipitar proteínas, os oxalatos, que podem precipitar com o cálcio, formando cristais insolúveis e cálculos renais nos indivíduos, e os fitatos, que podem formar complexos insolúveis com proteínas e minerais, havendo uma redução na biodisponibilidade destas importantes substâncias da dieta humana (HAMDANI; WANI, 2017; MANDEL, 1996).

No entanto, essas substâncias antinutricionais apresentam pequeno impacto na nutrição, pois são termolábeis; assim, são geralmente destruídas durante o preparo, na prática de deixar o feijão de molho à temperatura ambiente e descartar a água do molho, e, posteriormente, com o cozimento (OJIMELUKEW et al., 1995).

O consumo em quantidades de média a alta de feijão está sendo associado à diminuição de alguns tipos de câncer, menor incidência de doenças degenerativas e redução de doenças, como diabetes, doenças cardiovasculares e até mesmo neoplasias (AGUILERA; RIVERA, 1992; ROCHA-GUZMÁN et al., 2007; MACHADO et al., 2008). O feijão, ainda, associado a outros alimentos, auxilia na redução de incidência de anemia, devido a seu alto teor de ferro (PIRES et al., 2005; RIBEIRO et al., 2008).

Ferro é o componente de uma série de proteínas, incluindo enzimas e hemoglobina, sendo importante para o transporte do oxigênio para os tecidos. A deficiência de ferro ocorre quando as reservas nutricionais de ferro são esgotadas, devido principalmente à ingestão inferior ao necessário. Quando essa deficiência é severa, desenvolve-se a anemia por deficiência de ferro. De acordo com a World Health Organization (WHO, 2001), homens com mais de 19 anos necessitam de $8 \mathrm{mg} / \mathrm{dia}$; mulheres, dos 19 aos 50 anos, de $18 \mathrm{mg} / \mathrm{dia}$, e a partir de 51 anos, de $8 \mathrm{mg} / \mathrm{dia}$. Uma concha média (100 g) de feijão preto cozido apresenta $1,5 \mathrm{mg}$ de ferro. Outras fontes importantes de ferro são derivados de carnes (BORTOLINI; FISBERG, 2010).

Entretanto, a composição química dos grãos de feijão varia conforme a localização geográfica, as condições edáficas (tipo de solo, pH, fertilidade, textura, matéria orgânica, entre outros) e as variações climáticas (RIBEIRO, 2010).

Segundo a EMBRAPA (2015), o processo de biofortificação, conhecido também como melhoramento genético convencional, consiste no cruzamento de plantas da mesma espécie, gerando cultivares mais nutritivas; assim, reconhece-se, no projeto BioFORT, uma forma de melhorar a dieta dos brasileiros mais carentes. Dessa forma, como resultado do Programa de Melhoramento Genético do Feijoeiro Comum da Embrapa Arroz e Feijão, desenvolveram-se as cultivares de feijoeiros comuns com tipos de grãos carioca BRS Pontal e preto BRS Esplendor, objetivando-se alto potencial produtivo, maior resistência à colheita mecanizada e aporte nutricional (SILVA; WANDER, 2009; COSTA et al., 2011).

O objetivo deste trabalho foi determinar a composição centesimal e mineral de amostras de feijões comerciais e biofortificados, avaliando estatisticamente as semelhanças entre estes.

\section{Material e métodos}

Foram utilizadas quatro amostras de feijão comum (Phaseolus vulgaris L.): grãos preto e carioca, comercializados em supermercados na cidade de Cascavel-PR, e amostras biofortificadas: grão preto BRS Esplendor e grão carioca BRS Pontal, cultivados no mesmo período, safra inverno de 2016, por meio de cultivo convencional, em solo tipo latossolo roxo, terra roxa estruturada, na Fundetec (Fundação para o Desenvolvimento Científico e Tecnológico), localizada em Cascavel-PR, com Latitude: $24^{\circ} 57^{\prime} 21^{\prime \prime} \mathrm{S}$, Longitude: $53^{\circ} 27^{\prime} 19^{\prime \prime}$ W e Altitude: $781 \mathrm{~m}$. As amostras cruas foram trituradas em moinho de facas e peneiradas em malha de 30 "mesh", sendo então cozidas: foram previamente hidratadas com água destilada na proporção de 1:3, por 24 horas, e posteriormente mantidas em panela de pressão por 20 minutos.

\subsection{Composição centesimal}

As análises foram efetuadas em triplicata, no Laboratório de Análises da Fundetec. O teor de umidade das amostras foi estabelecido segundo método gravimétrico a $105^{\circ} \mathrm{C}$; o resíduo mineral fixo, por incineração a $550^{\circ} \mathrm{C}$; o método micro de Kjeldahl com fator de conversão do nitrogênio total de 6,25 foi utilizado para avaliação do teor de proteína total; os lipídios totais foram analisados por extração Soxhlet, utilizando-se, como solvente, o éter de petróleo. Todas as análises foram realizadas segundo as Normas Analíticas do Instituto Adolfo Lutz (IAL, 2008). A determinação de carboidratos foi realizada por diferença, subtraindo-se de 100 a soma dos teores de lipídios, proteínas, umidade e cinzas. 


\subsection{Teor mineral}

Os minerais ferro, potássio, magnésio e sódio foram determinados pelo método descrito por Moura e Canniatti-Brazaca (2006): as amostras foram submetidas à digestão com ácido clorídrico e nítrico, numa proporção de 2:1, com $0,3 \mathrm{~g}$ das amostras mantido a $200^{\circ} \mathrm{C}$, por 4 horas, sendo então realizada leitura em espectrofotômetro de emissão atômica por plasma acoplado (ICP-OES) da ThermoScientific.

\subsection{Análise estatística dos dados}

Os resultados das análises físico-químicas foram submetidos à análise de variância (ANOVA) e a comparação de médias foi realizada pelo teste de Tukey, no nível de 5\% de significância, utilizando-se o software Minitab 17.

\section{Resultados e discussão}

A Tabela 1 apresenta os resultados dos ensaios de caracterização das amostras de feijão quando cruas, observando-se que o teor de lipídios variou entre 1,15 e 1,78 g.100 g-1. Mesquita et al. (2007) encontraram um valor mínimo de 0,53 g. $100 \mathrm{~g}^{-1}$ e máximo de 2,55 g. $100 \mathrm{~g}^{-1}$ de gordura em feijão cru, estando de acordo com os dados apresentados.

Para o teor de proteína, o feijão BRS Pontal apresentou o maior valor, 22,47 g.100 g-1, diferindo estatisticamente das demais variedades. O feijão BRS Esplendor foi o que apresentou menor teor proteico, 18,29 g.100 g ${ }^{-1}$. Autores de trabalhos anteriores reportaram valores variando entre 17,72 e 31,59 g. $100 \mathrm{~g}^{-1}$ (PIRES et al., 2005; MARQUEZI et al., 2016; BRIGIDE et al., 2014).
O teor de umidade das diferentes variedades

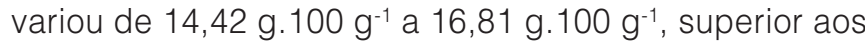
valores médios encontrados por Oliveira et al. (2001) e Nalepa e Ferreira (2013), de 9,4 g.100 g-1 e 12,08 g.100 g ${ }^{-1}$, respectivamente, e próximo ao encontrado por Brigide et al. (2014), de 14,43 g. $100 \mathrm{~g}^{-1}$. A variedade de feijão BRS Pontal apresentou o maior teor de umidade, $16,81 \mathrm{~g} .100 \mathrm{~g}^{-1} \mathrm{e}$ diferiu estatisticamente das demais variedades. No que se refere aos teores de cinzas, a variedade de feijão BRS Esplendor apresentou maior teor, 4,11 g.100 g-1 (Tabela 1), diferindo estatisticamente $(p<0,05)$ das demais variedades, sendo todos os valores dentro da faixa encontrada, em estudos anteriores, de 2,97 a 4,87 g.100 g-1 (MESQUITA et al., 2007; RAMÍREZ-CÁRDENASI et al., 2008).

O teor de ferro das diferentes variedades está apresentado na Tabela 2, tendo apresentado teores médios maiores, as variedades de feijão biofortificadas: BRS Pontal $\left(8,16 \mathrm{mg} 100 \mathrm{~g}^{-1}\right)$ e BRS Esplendor ( $\left.8,25 \mathrm{mg} \cdot 100 \mathrm{~g}^{-1}\right)$, sendo que os valores não diferiram entre si significativamente $(p<0,05)$, mas mostraram diferença dos valores das amostras comerciais de feijão carioca. Em estudos anteriores, foram encontrados valores do teor de ferro em amostras de feijão variando entre 4,46 e 9,16 mg.100 g-1 , próximos aos encontrados neste trabalho (PIRES et al., 2005; RAMÍREZ-CÁRDENASI et al., 2008).

As cultivares biofortificadas apresentaram ainda valores maiores de potássio, diferindo estatisticamente das cultivares comerciais.

Dentre os resultados dos teores de lipídios dos feijões analisados após a cocção, apresentados na Tabela 3, nota-se que o teor de lipídios das cultivares biofortificadas é aproximadamente $80 \%$ inferior às variedades comuns. O feijão comum apresenta grande variabilidade na

Tabela 1. Composição centesimal das cultivares de feijão (Phaseolus vulgaris L.) cru.

\begin{tabular}{|c|c|c|c|c|c|}
\hline Cultivar & $\begin{array}{l}\text { Lipídios }^{(1)} \\
\text { g.100 } \text { g }^{-1}\end{array}$ & $\begin{array}{l}\text { Proteína }{ }^{(1)} \\
\text { g.100 } \mathrm{g}^{-1}\end{array}$ & $\begin{array}{c}\text { Umidade } \\
\text { g.100 } \mathrm{g}^{-1}\end{array}$ & $\begin{array}{l}\text { Cinzas(1) }^{(1)} \\
\text { g.100 g }\end{array}$ & $\begin{array}{c}\text { Carboidratos }^{(2)} \\
\text { g.100 g-1 }\end{array}$ \\
\hline Feijão Carioca & $1,15 \pm 0,05^{c}$ & $19,76 \pm 0,80^{b}$ & $14,42 \pm 0,37^{b}$ & $3,43 \pm 0,02^{b}$ & 61,25 \\
\hline Feijão Preto & $1,44 \pm 0,06^{b}$ & $20,21 \pm 1,08^{a b}$ & $15,47 \pm 0,71^{b}$ & $3,33 \pm 0,09^{b}$ & 59,55 \\
\hline Feijão BRS Pontal & $1,44 \pm 0,09^{b}$ & $22,47 \pm 1,07^{a}$ & $16,81 \pm 0,24^{a}$ & $3,48 \pm 0,13^{b}$ & 55,80 \\
\hline Feijão BRS Esplendor & $1,78 \pm 0,14^{a}$ & $18,29 \pm 0,86^{b}$ & $15,14 \pm 0,12^{b}$ & $4,11 \pm 0,03^{a}$ & 60,68 \\
\hline
\end{tabular}

(1) Valores das médias das triplicatas \pm desvio padrão; (2) Calculado pela Equação (100 - Lipídios - Proteína - Umidade - Cinzas). Letras diferentes na mesma coluna indicam diferença significativa $(p<0,05)$, pelo teste de Tukey.

Tabela 2. Conteúdo mineral das cultivares de feijão (Phaseolus vulgaris L.) cru.

\begin{tabular}{|c|c|c|c|c|}
\hline Cultivar & $\begin{array}{c}\text { Ferro } \\
\text { mg.100 } \text { g }^{-1}\end{array}$ & $\begin{array}{l}\text { Potássio } \\
\mathrm{mg} 100 \mathrm{~g}^{-1}\end{array}$ & $\begin{array}{l}\text { Magnésio } \\
\mathrm{mg}^{100} \mathrm{~g}^{-1}\end{array}$ & $\begin{array}{c}\text { Sódio } \\
\text { mg.100 g-1 }\end{array}$ \\
\hline Feijão Carioca & $7,7 \pm 0,12^{\star b}$ & $1389,48 \pm 31,43^{b}$ & $210,81 \pm 8,59^{a}$ & $1,02 \pm 0,12^{a}$ \\
\hline Feijão Preto & $6,52 \pm 0,13^{b}$ & $1408,56 \pm 9,64^{b}$ & $186,83 \pm 1,21^{b}$ & $1,07 \pm 0,13^{a}$ \\
\hline Feijão BRS Pontal & $8,16 \pm 0,30^{a}$ & $1465,06 \pm 6,03^{a}$ & $212,61 \pm 4,41^{a}$ & $1,00 \pm 0,30^{a}$ \\
\hline Feijão BRS Esplendor & $8,25 \pm 0,26^{a}$ & $1473,4 \pm 9,55^{a}$ & $188,1 \pm 1,80^{b}$ & $1,02 \pm 0,26^{a}$ \\
\hline
\end{tabular}

* Valores das médias das triplicatas \pm desvio padrão. Letras diferentes na mesma coluna indicam diferença significativa $(p<0,05)$, pelo teste de Tukey. 
composição de ácidos graxos e substancial quantidade de ácidos graxos insaturados, que são imprescindíveis para a nossa saúde (REYES-MORENO et al., 1993). Assim, a redução do teor dos lipídios nas variedades pode ser considerada uma desvantagem da biofortificação.

Ramírez-Cárdenasi et al. (2008) relataram, em seu estudo, ao avaliarem o efeito do processamento doméstico em cinco cultivares de feijão comum, os seguintes teores: lipídios: 1,81 a 2,32 g. $100 \mathrm{~g}^{-1}$; proteína: 22,24 a 26,09 g. $100 \mathrm{~g}^{-1}$, e cinzas: 3,66 a 4,30 g.100 g-1. Silva et al. (2013) encontraram, ao avaliarem a composição centesimal de grãos crus e cozidos de cultivares comerciais e biofortificadas, valores de lipídios entre 1,84 g.100 g-1 (feijão biofortificado) e 2,33 g.100 $\mathrm{g}^{-1}$ (feijão comercial); proteína, entre 23,42 g.100 g-1 (feijão comercial) e 26,56 g.100 $\mathrm{g}^{-1}$ (feijão biofortificado), e cinzas, entre 3,96 g.100 g-1 (feijão biofortificado) e 4,01 g.100 $\mathrm{g}^{-1}$ (feijão comercial). Todos os valores relatados estão próximos aos encontrados neste estudo.

Para o teor de ferro, observou-se (Tabela 4) que as cultivares biofortificadas apresentaram maiores valores: BRS Esplendor, com 1,67 mg.100 $\mathrm{g}^{-1}$ e BRS Pontal com 1,64 mg.100 g ${ }^{-1}$, não diferindo estatisticamente entre si e com a cultivar comercial do feijão tipo preto, acompanhando a tendência dos grãos crus. Isto pode ser justificado pelo fato de a composição química dos alimentos variar conforme a localização geográfica, as condições edáficas e as variações climáticas em que foram cultivados (RIBEIRO, 2010). É importante ressaltar que as cultivares biofortificadas foram cultivadas nas mesmas condições, enquanto que as informações de cultivo das cultivares adquiridas em supermercados são desconhecidas.
As cultivares biofortificadas apresentaram também valores mais altos de potássio.

A Tabela Brasileira de Composição de Alimentos (UNICAMP, 2011) utiliza, como valor médio, para os teores de ferro para os feijões cozidos carioca e preto, 1,3 e 1,5 mg. $100 \mathrm{~g}^{-1}$, respectivamente, valores estes inferiores aos encontrados no presente estudo. Os teores de potássio, segundo a referida tabela, são 255 e 256 mg. $100 \mathrm{~g}^{-1}$ para os feijões carioca e preto, respectivamente, próximos aos encontrados nas amostras comerciais e inferiores às biofortificadas.

A digestão ácida de alimentos, utilizada no presente trabalho, pode acarretar contaminação ou perda do analito por adsorção ou volatilização, sendo atualmente a metodologia de digestão via micro-ondas a mais indicada para posterior análise de minerais. Dessa forma, além do fato de a composição química dos grãos poder ter sido afetada pelas variações climáticas e pelos fatores edáficos, podem também ter ocorrido perdas dos teores de minerais, devido à forma de digestão utilizada no estudo.

Observou-se um pequeno aumento dos teores de lipídios, proteína, cinzas e, por consequência, de carboidratos, nos grãos após a cocção, mostrando que o processamento de leguminosas praticamente não altera a sua composição (Silva et al., 2013). Em relação à composição mineral, não se podem fazer comparações entre os grãos crus e cozidos, uma vez que os grãos cozidos não foram analisados em base seca, com relação aos minerais.

Verificou-se, por meio das análises realizadas, que a biofortificação aumentou o teor de ferro, potássio e magnésio, comparando-se os resultados obtidos, dos grãos crus e cozidos, dos feijões comercializados e dos feijões biofortificados, porém não de forma significativa,

Tabela 3. Composição centesimal das cultivares de feijão (Phaseolus vulgaris L.) cozido (em base seca).

\begin{tabular}{|c|c|c|c|c|}
\hline Cultivar & $\begin{array}{l}\text { Lipídios }^{(1)} \\
\text { g.100 } \mathrm{g}^{-1}\end{array}$ & $\begin{array}{l}\text { Proteína }{ }^{(1)} \\
\text { g.100 g-1 }\end{array}$ & $\begin{array}{l}\text { Cinzas } \\
\text { g.100 } \mathrm{g}^{-1}\end{array}$ & $\begin{array}{c}\text { Carboidratos }^{(2)} \\
\text { g.100 g- }\end{array}$ \\
\hline Feijão Carioca & $2,30 \pm 0,03^{\star a}$ & $26,51 \pm 0,09^{b}$ & $3,63 \pm 0,02^{c}$ & 67,56 \\
\hline Feijão Preto & $2,09 \pm 0,24^{a}$ & $24,67 \pm 0,04^{c}$ & $3,47 \pm 0,02^{b c}$ & 69,77 \\
\hline Feijão BRS Pontal & $1,53 \pm 0,04^{b}$ & $32,08 \pm 0,15^{a}$ & $3,86 \pm 0,05^{b}$ & 63,52 \\
\hline Feijão BRS Esplendor & $1,52 \pm 0,09^{b}$ & $20,83 \pm 0,08^{d}$ & $3,87 \pm 0,04^{a}$ & 74,78 \\
\hline
\end{tabular}

(1) Valores das médias das triplicatas \pm desvio padrão; (2) Calculado pela Equacão (100 - Lipídios - Proteína - Umidade - Cinzas); ${ }^{*}$ Letras diferentes na mesma coluna indicam diferença significativa $(p<0,05)$, pelo teste de Tukey.

Tabela 4. Conteúdo mineral das cultivares de feijão (Phaseolus vulgaris L.) cozido.

\begin{tabular}{|c|c|c|c|c|}
\hline Cultivar & $\begin{array}{c}\text { Ferro } \\
\mathrm{mg} 100 \mathrm{~g}^{-1}\end{array}$ & $\begin{array}{l}\text { Potássio } \\
\text { mg.100 g-1 }\end{array}$ & 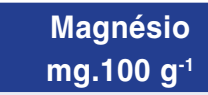 & $\begin{array}{c}\text { Sódio } \\
\mathrm{mg} .100 \mathrm{~g}^{-1}\end{array}$ \\
\hline Feijão Carioca & $1,41 \pm 0,13^{\star b}$ & $250,36 \pm 8,73^{b}$ & $42,81 \pm 1,20^{a}$ & $1,01 \pm 0,03^{a}$ \\
\hline Feijão Preto & $1,46 \pm 0,09 b$ & $254,48 \pm 4,28^{a b}$ & $42,06 \pm 2,05^{a}$ & $1,03 \pm 0,01^{a}$ \\
\hline Feijão BRS Pontal & $1,64 \pm 0,07^{a}$ & $264,73 \pm 4,23^{a b}$ & $44,12 \pm 0,42^{a}$ & $1,03 \pm 0,02^{a}$ \\
\hline Feijão BRS Esplendor & $1,67 \pm 0,03^{a}$ & $267,32 \pm 4,10^{a}$ & $44,04 \pm 0,99^{a}$ & $1,01 \pm 0,01^{a}$ \\
\hline
\end{tabular}

*Valores das médias das triplicatas \pm desvio padrão. Letras diferentes na mesma coluna indicam diferença significativa $(p<0,05)$, pelo teste de Tukey. 
uma vez que as cultivares biofortificadas, em determinadas análises, não diferiram estatisticamente das comerciais. Contudo, os processos devem ser aprimorados nas condições de cultivo e o feijão, como alimento auxiliar na redução da incidência de anemias, devido à presença do mesmo no dia-a-dia do brasileiro, deve ser de fácil preparo e de conservação.

\section{Conclusões}

A biofortificação aumentou, porém não significativamente, os teores de ferro, potássio e magnésio nas cultivares de feijão. Tal fato pode ter ocorrido devido à variação da composição química das cultivares, ocasionada pelos fatores edáficos e climáticos, ou por perdas ocasionadas pela digestão ácida, realizada no estudo.

Foi verificada também uma desvantagem da biofortificação relacionada à redução lipídica dos grãos, sendo estes compostos por ácidos graxos importantes para a nossa saúde.

Assim, a biofortificação deve ser aprimorada, a fim de regular e melhorar os nutrientes das cultivares. Porém, percebe-se que cultivares de feijão biofortificadas podem ser usadas para auxiliar na redução da incidência de anemias, uma vez que já está presente na alimentação dos brasileiros.

Faz-se necessária a realização de mais pesquisas, eliminando o efeito dos fatores edáficos e climáticos na composição química das cultivares, e utilizando digestão via micro-ondas para analisar posteriormente os minerais. Mostram-se também importantes as pesquisas dos fatores antinutricionais presentes nas cultivares de feijão.

\section{Agradecimentos}

À Embrapa pelo fornecimento das sementes das amostras biofortificadas.

\section{Referências}

AGUILERA, J. M.; RIVERA, R. Hard-to-cook defect in black beans: hardening rates, water imbibition and multiple mechanism hypothesis. Food Research International, v. 25, n. 2, p. 101-108, 1992. http://dx.doi.org/10.1016/0963-9969(92)90150-4.

BENEVIDES, C. M. J.; SOUZA, M. V.; SOUZA, R. D. B.; LOPES, M. V. Fatores antinutricionais em alimentos: revisão. Segurança Alimentar e Nutricional, v. 18, n. 2, p. 67-79, 2011.

BORTOLINI, G. A.; FISBERG, M. Orientação nutricional do paciente com deficiência de ferro. Revista Brasileira de Hematologia e Hemoterapia, v. 32, p. 105-113, 2010. http://dx.doi.org/10.1590/ S1516-84842010005000070.

BRASIL. Ministério da Agricultura, Pecuária e Abastecimento. Instrução normativa $n^{\circ} 12$, de 28 de março de 2008. Regulamento técnico do feijão. Diário Oficial [da] República Federativa do Brasil, Brasília, DF, 31 mar. 2008. Seção 1.

BRIGIDE, P.; CANNIATTI-BRAZACA, S. G.; SILVA, M. O. Nutritional characteristics of biofortifed common beans. Food Science and Technology, v. 34, n. 3, p. 493-500, 2014.

COSTA, J. G. C.; MELO, L. C.; PEREIRA, H. S.; DEL PELOSO, M. J.; FARIA, L. C.; DÍAZ, J. L. C.; WENDLAND, A.; RAVA, A. BRS Esplendor: common bean cultivar with black grain, upright growth and disease resistance. Crop Breeding and Applied Biotechnology, v. 11, n. 3, p. 276-279, 2011. http://dx.doi. org/10.1590/S1984-70332011000300011.

EMPRESA BRASILEIRA DE PESQUISA AGROPECUÁRIA EMBRAPA. Alimentos biofortificados buscam reduzir a desnutrição da população. Brasília: EMBRAPA, 2015.

HAMDANI, A. M.; WANI, I. A. Guar and Locust bean gum: composition, total phenolic content, antioxidant and antinutritional characterisation. Bioactive Carbohydrates and Dietary Fibre, v. 11, p. 53-59, 2017. http://dx.doi.org/10.1016/j.bcdf.2017.07.004.

INSTITUTO ADOLFO LUTZ - IAL. Métodos físico-químicos para análise de alimentos. São Paulo: Instituto Adolfo Lutz, 2008. $1020 \mathrm{p}$.

MACHADO, C. M.; FERRUZZI, M. G.; NIELSEN, S. S. Impact of the hard-to-cook phenomenon on phenolic antioxidants in dry beans (Phaseolus vulgaris). Journal of Agricultural and Food Chemistry, v. 56, n. 9, p. 3102-3110, 2008. PMid:18416551. http://dx.doi.org/10.1021/jf072861y.

MANDEL, N. Mechanism of stone formation. Seminars in Nephrology, v. 16, n. 5, p. 364-374, 1996. PMid:8890393.

MARQUEZI, M.; GERVIN, V. M.; WATANABE, L. B.; BASSINELLO, P. Z.; AMANTE, E. R. Physical and chemical properties of starch and flour from different common bean (Phaseolus vulgaris L.) cultivars. Brazilian Journal of Food Technology, v. 19, 2016. http://dx.doi.org/10.1590/1981-6723.0516.

MESQUitA, F. R.; CORREA, A. D.; ABREU, C. M. P.; LIMA, R. A. Z.; ABREU, A. F. B. Linhagens de feijão (Phaseolus vulgaris L.): composição química e digestibilidade protéica. Ciência e Agrotecnologia, v. 31, n. 4, p. 1114-1121, 2007. http://dx.doi. org/10.1590/S1413-70542007000400026.

MOURA, N. C.; CANNIATTI-BRAZACA, B. S. G. Avaliação da disponibilidade de ferro de feijão comum (Phaseolus vulgaris L.) em comparação com carne bovina. Ciência e Tecnologia de Alimentos, v. 26, n. 2, p. 270-276, 2006. http://dx.doi.org/10.1590/ S0101-20612006000200007.

NALEPA, K. C.; FERREIRA, S. M. R. Avaliação da qualidade do feijão preto. Demetra, v. 8, n. 2, p. 115-124, 2013.

OJIMELUKEW, P. C.; ONUOHA, C. C.; OBANU, Z. A. Effects of processing and in vitro proteolytic digestion on soybean and yambean hemagglutinins. Plant Foods for Human Nutrition, 
v. 47, n. 4, p. 293-299, 1995. PMid:8577646. http://dx.doi. org/10.1007/BF01088266.

OliveIRA, A. C.; QUEIROZ, K. S.; HELBIG, E.; REIS, S. M. P. M.; CARRARO, F. O processamento doméstico do feijão-comum ocasionou uma redução nos fatores antinutricionais fitatos e taninos, no teor de amido e em fatores de flatulência rafinose, estaquiose e verbascose. Archivos Latinoamericanos de Nutricion, v. 51, n. 3, p. 276-283, 2001. PMid:11795242.

PELOSO, M. J. D.; MELO, L. C. Potencial de rendimento da cultura do feijoeiro comum. Santo Antônio de Goiás: Embrapa Arroz e Feijão, 2005. 131 p.

PIRES, C. V.; OLIVEIRA, M. A. G.; CRUZ, G. A. D. R.; MENDES, F. Q.; REZENDE, S. T.; MOREIRA, M. A. Physicochemical composition of different cultivars of beans (Phaseolus vulgaris L.). Alimentação e Nutrição, v. 16, p. 157-162, 2005.

RAMÍREZ-CÁRDENASI, L.; LEONEL, A. J.; COSTA, N. M. B. Efeito do processamento doméstico sobre o teor de nutrientes e de fatores antinutricionais de diferentes cultivares de feijão comum. Ciência e Tecnologia de Alimentos, v. 28, n. 1, p. 200-213, 2008. http://dx.doi.org/10.1590/S0101-20612008000100029.

REYES-MORENO, C.; PAREDES-LÓPEZ, O.; GONZALEZ, E. Hardto-cook phenomenon in common beans: a review. CRC Critical Reviews in Food Science and Nutrition, v. 33, n. 3, p. 227-286, 1993. PMid:8484867. http://dx.doi.org/10.1080/10408399309527621.

RIBEIRO, N. D. Potencial de aumento da qualidade nutricional do feijão por melhoramento genético. Semina: Ciências Agrárias, v. 31, n. 4, p. 1367-1376, 2010. Suplemento 1. http://dx.doi. org/10.5433/1679-0359.2010v31n4Sup1p1367.

RIBEIRO, N. D.; JOST, E.; CERUTTI, T.; MAZIERO, S. M.; POERSCH, N. L. Composição de microminerais em cultivares de feijão e aplicações para o melhoramento genético. Bragantia, v. 67, n. 2 , p. 267-273, 2008. http://dx.doi.org/10.1590/S000687052008000200002.

ROCHA-GUZMÁN, N. E.; GONZÁLEZ-LAREDO, R. F.; IBARRAPÉREZ, F. J.; NAVA-BERÚMEN, C. A.; GALLEGOS-INFANTE, J.-A. Effect of pressure cooking on the antioxidant activity of extracts from three common bean (Phaseolus vulgaris L.) cultivars. Food Chemistry, v. 100, n. 1, p. 31-35, 2007. http://dx.doi.org/10.1016/j. foodchem.2005.09.005.

SANTOS, M. A. T. Efeito do cozimento sobre alguns fatores antinutricionais em folhas de brócoli, couve-flor e couve. Ciência e Agrotecnologia, v. 30, n. 2, p. 294-301, 2006. http://dx.doi. org/10.1590/S1413-70542006000200015.

SILVA, A. G.; ROCHA, L. C.; CANNIATTI, B. S. G. Physico-chemical characterization, protein digestibility and antioxidant activity of commun bean (Phaseolus vulgaris L.). Alimentos e Nutrição, v. 20, n. 4, p. 591-598, 2009.

SILVA, M. O.; BRIGIDE, P.; CANNIATTI-BRAZACA, S. G. Caracterização da composição centesimal e mineral de diferentes cultivares de feijão comum crus e cozidos. Alimentos e Nutrição, v. 24, n. 3, p. 339-346, 2013.

SILVA, O. F.; WANDER, A. E. Impacto econômico da cultivar de feijão tipo carioca BRS Pontal. Santo Antônio de Goiás: EMBRAPA, 2009. (Comunicado Técnico, 172).

UNIVERSIDADE ESTADUAL DE CAMPINAS - UNICAMP. Núcleo de Estudos e Pesquisas em Alimentação - NEPA. Tabela Brasileira de Composição de Alimentos (TACO). Campinas: UNICAMP, 2011. 164 p.

WORLD HEALTH ORGANIZATION - WHO. Iron deficiency anemia: assessment, prevention and control. Geneva: WHO, 2001. p. 132. 